\title{
Sternomastoid muscle fatigue and twitch maximum relaxation rate in patients with steroid dependent asthma
}

\author{
V H F Mak, J R Bugler, S G Spiro
}

\begin{abstract}
Background-Long term oral corticosteroid treatment is a cause of myopathy of the skeletal muscles. The effect of long term treatment with oral corticosteroids on the respiratory muscles is uncertain. Respiratory muscle function and fatigue in sternomastoid muscle were investigated in a group of patients with chronic severe asthma who were taking oral corticosteroids. The results were compared with those from a group of patients with chronic airflow limitation who were not taking oral steroids.
\end{abstract}

Methods-Twelve patients with chronic severe asthma, taking a mean daily dosage of $8 \mathrm{mg}$ of prednisolone for a mean (SD) of $16.8(9.1)$ years, were compared with patients with chronic airflow limitation and individually matched for sex, age, and severity of airflow limitation. Lung function tests, maximal mouth pressures, and quadriceps and sternomastoid muscle strength were measured. The sternomastoid muscle was fatigued by maximal headlift exercise to $70 \%$ of initial headlift force and the endurance time noted. Sternomastoid fatigue was assessed by twitch maximum relaxation rate (TMRR) measured in the fresh state and for $\mathbf{3 0}$ minutes after exercise.

Results-There was no significant difference between the control group and the corticosteroid group for maximal mouth pressures, fresh state TMRR, and quadriceps and sternomastoid strength. The control group had a significantly longer mean (SD) endurance time than the corticosteroid group (121 (47) s $v 86$ (24) s), and also had significantly less slowing and faster recovery of the TMRR after exercise. The slowing and recovery of the TMRR in the corticosteroid group, however, was similar to that previously reported for normal subjects.

Conclusion-Respiratory muscle weakness does not occur more often in patients taking oral corticosteroids. The corticosteroid group was more prone to fatigue than the control group, but was similar to normal subjects. This suggests that chronic airflow limitation may produce a training effect on the respiratory muscles that might be attenuated by long term oral corticosteroid treatment.

\section{(Thorax 1993;48:979-984)}

Despite the widespread use of potent topical inhaled corticosteroids for the treatment of asthma, some patients with chronic severe asthma remain dependent on long term oral corticosteroid treatment to control their symptoms. These patients are at risk from the well known systemic side effects of oral corticosteroids, which include adrenal suppression, osteoporosis, impaired carbohydrate metabolism, truncal obesity, dermal thinning, and myopathy. Corticosteroid induced myopathy has been described mainly in the proximal skeletal muscles ${ }^{1-3}$ and is usually related to long term treatment. Myopathy of the peripheral muscles has been described in asthmatic patients given long term oral corticosteroid treatment ${ }^{4}$ and also in patients given short periods of treatment with intravenous steroids. ${ }^{56}$

Little is known about the effects of long term oral corticosteroid treatment on the function of the respiratory muscles. If corticosteroid induced myopathy also involves the respiratory muscles, this could predispose to weakness and fatigue of these muscles and subsequent respiratory failure. To date, studies have not shown obvious respiratory muscle weakness in patients with respiratory disease given steroids. ${ }^{48}$ It is not known, however, if long term corticosteroid treatment makes the respiratory muscles prone to fatigue.

We have previously described a simple and sensitive test to detect fatigue in an accessory muscle of respiration - namely, the slowing of the sternomastoid muscle twitch maximum relaxation rate (TMRR). ${ }^{9}$ The TMRR of certain muscles in animals is slower in muscles with myopathy induced by corticosteroids. ${ }^{1011}$ Therefore, the TMRR of the sternomastoid muscle may serve as an indicator of corticosteroid induced myopathy in the respiratory muscles in humans.

We have investigated respiratory muscle function and sternomastoid muscle fatigue with the sternomastoid TMRR technique in a group of patients with chronic severe asthma requiring long term oral corticosteroid treatment. 


\section{Patients and methods}

PATIENTS

We studied 12 patients with chronic severe asthma requiring long term oral corticosteroid treatment. All had a well documented history of variability of lung function responsive to oral corticosteroid treatment, but could not be weaned off their oral corticosteroids despite high dose inhaled corticosteroid medication. All had been taking oral corticosteroids for at least two years before the study. Patients were studied in a stable clinical condition on their minimum maintenance oral corticosteroid dose plus their usual medications, which included high dose inhaled corticosteroids ( $>1500 \mu \mathrm{g} /$ day beclomethasone), inhaled $\beta_{2}$ agonists, ipratropium bromide and, in four patients, oral theophyllines.

It was possible to individually match these patients with a control group of patients with chronic airflow limitation who had never taken regular oral steroids. The two groups were matched for sex, age, height, and indices of airflow limitation and hyperinflation. All had previously received one or two short courses (< two weeks) of oral corticosteroids for acute exacerbations or as a steroid trial during the course of their disease, but none for at least six months before the study. The control group was also studied in a stable clinical condition on their usual medication, which included inhaled $\beta_{2}$ agonists, ipratropium bromide and, in five patients, oral theophyllines. Eight of the 12 were also taking inhaled corticosteroids $(<1000 \mu \mathrm{g} /$ day of beclomethasone).

We also studied 18 patients with chronic severe asthma requiring long term oral corticosteroid treatment whom we could not match, and include data from these patients to compare with the smaller group of 12 patients taking corticosteroids.

No patients had any evidence of neuropathic or joint disorders that would have impaired their ability to carry out the tests on muscle strength and endurance. Two patients taking long term oral corticosteroids had complained in the past of muscle weakness, especially of the legs. All patients gave written informed consent and the study was approved by the ethics committee of University College Hospital.

\section{LUNG FUNCTION STUDIES}

All patients underwent detailed lung function tests. Spirometry and peak flow were measured with a computerised dry rolling seal spirometer (Gould Pulmograph System 2130, UK). Total lung capacity (TLC) and lung volume subdivisions were calculated from measuring thoracic gas volume in a constant volume whole body plethysmograph (Fenyves and Gut, Switzerland). At least three measurements were made for each variable. Predicted values were obtained from regression equations given in Cotes. ${ }^{12}$

RESPIRATORY MUSCLE STRENGTH

Respiratory muscle strength was assessed by maximal mouth pressures with a technique adapted from Black and Hyatt. ${ }^{13} \mathrm{~A}$ mouthpiece was attached to a rigid perspex tube 30 $\mathrm{cm}$ in length and $3 \mathrm{~cm}$ internal diameter. The tube had a $1.5 \mathrm{~mm}$ diameter leak hole $15 \mathrm{~cm}$ down its length to prevent closure of the glottis during respiratory manoeuvres. The pressure generated within the tube was measured with a Medex vascular pressure transducer (Medex Inc, Rossendale, UK) attached to the end of the tube. This system has been validated for measuring respiratory pressures and has a precision of $\pm 2 \% .{ }^{14}$ Maximum inspiratory pressure (PImax) was measured from residual volume and maximum expiratory pressure (PEmax) was measured at total lung . capacity with the patients' palms pressing against their cheeks to prevent any contribution from the buccal musculature. The maxi- $\overrightarrow{\vec{x}}$ mal pressure sustained for at least one second was recorded and the best of four attempts taken. Reference values previously established by our laboratory with this technique were used. ${ }^{15}$

\section{STERNOMASTOID MUSCLE STRENGTH AND}

\section{ENDURANCE}

Sternomastoid muscle strength was assessed by measuring the maximum voluntary headlift force. The patients lay on a couch with their head and shoulders resting on a pillow at an angle of 30-45 degrees. Patients were asked to lift their foreheads a few centimetres from the resting position and to push as hard as possible against a pad attached to a load cell (Dyanometer UF-2, Ormed, UK) secured above them. The headlift force thus $\overrightarrow{\hat{O}}$ obtained was recorded on a chart recorder and calculated in Newtons (N). The best of four attempts was taken. Seventy per cent of the maximum headlift force was calculated and marked on the chart recorder. The patients were then exercised by performing repeated maximal headlifts against the fixed pad for two seconds followed by two seconds rest (giving a tension/time index of $50 \%$ ). 3 This exercise was continued until each sub- 0 ject could not achieve $70 \%$ of their initial maximum headlift force on three consecutive attempts despite active encouragement. The time taken to this point was recorded as the $\sigma$ endurance time.

\section{STERNOMASTOID FATIGUE}

Sternomastoid fatigue was assessed from the sternomastoid twitch maximum relaxation $\bar{D}$ rate. Full details of this technique have been described previously. ${ }^{9}$ Briefly, patients were studied lying at an angle of 30-45 degrees. The right sternomastoid muscle was stimulated with two electrodes (3M Red Dot ECG $\cong$ electrode), one placed on the sternum and the other placed over the insertion of the $\delta$ accessory nerve into the body of the muscle. The anterior force vector generated by the muscle contraction was measured with a load $\rightleftharpoons$ cell (Dyanometer UF-2, Ormed, UK) attached to a curved perspex head pressed firmly on to the medial (sternal) tendon of the muscle. The load cell was in turn 
attached to a custom designed rigid metal frame that allowed adjustments in several directions to simplify ideal placement.

The muscle was electrically stimulated with a unidirectional square wave impulse of $50 \mu \mathrm{s}$. Twitches were recorded with a UV light sensitive chart recorder running at $100 \mathrm{~mm} / \mathrm{s}$ (Micromovements, UK). Initially, maximal stimulation voltage was determined by measuring the twitch force response to increasing voltages and was taken as the lowest voltage that gave a maximal twitch response (usually $50-80 \mathrm{~V}$ ). Stimulation voltage for each patient was set at $10 \mathrm{~V}$ above the maximal voltage (to ensure supramaximal stimulation) and all twitches performed at $1 \mathrm{~Hz}$ with the breath held at end tidal expiration. Up to eight twitches could be performed during each breathhold. At least 24 twitches were measured in the fresh state. After the endurance exercise protocol, twitches were recorded at $1,2 \cdot 5,5,7 \cdot 5,10,15$, and 30 minutes, with at least eight twitches on each occasion.

All recorded twitches were analysed by hand. The TMRR was taken as the slope of the tangent drawn against the steepest part of the relaxation curve (usually the initial $10-50 \%$ of the curve) normalised for the peak twitch force, and expressed as \% force loss $/ 10$ ms. Any twitch that did not have a smooth relaxation curve was rejected. At least six acceptable twitches were used to calculate the mean TMRR for each period after exercise.

\section{PERIPHERAL MUSCLE STRENGTH}

Peripheral muscle strength was assessed from the quadriceps muscle with a standard quadriceps chair. ${ }^{16}$ The leg was held in passive flexion with an ankle strap attached to a custom built strain gauge. Patients were asked to make maximal extension movements at the knee against the ankle strap. The force produced was recorded on a chart recorder. The best of four attempts was used and force was calculated in Newtons (N). Predicted values for quadriceps strength were calculated from equations based on age, sex and height,

Table 1 Mean (SD) data for age and lung function

\begin{tabular}{|c|c|c|c|}
\hline & $\begin{array}{l}\text { Control group } \\
(n=12)\end{array}$ & $\begin{array}{l}\text { Corticosteroid } \\
\text { group }(n=12)\end{array}$ & $\begin{array}{l}\text { Additional } \\
\text { corticosteroid } \\
\text { patients }(n=18)\end{array}$ \\
\hline $\mathrm{M} / \mathrm{F}$ & $6 / 6$ & $6 / 6$ & $8 / 10$ \\
\hline Age (y) & $61 \cdot 4(9 \cdot 3)$ & $59.5(10.4)$ & $57 \cdot 1(14 \cdot 9)$ \\
\hline Height (m) & $1.63(0.11)$ & $1.64(0.11)$ & $1.67(0 \cdot 14)$ \\
\hline $\begin{array}{l}\text { Average daily dose } \\
\text { prednisolone (mg) }\end{array}$ & N/A & $8 \cdot 00(2 \cdot 8)$ & $8 \cdot 00(3 \cdot 11)$ \\
\hline Duration of treatment $(y)$ & N/A & $16 \cdot 8(9 \cdot 1)$ & $13.3(9.5)$ \\
\hline Peak flow ( $1 / \mathrm{min})$ & $160(75)$ & $189(89)$ & $278(88)^{\star}$ \\
\hline $\mathrm{FEV}_{1}(\mathrm{l})$ & $1.10(0.46)$ & $1.19(0.55)$ & $1.92(0.55)^{\star}$ \\
\hline FVC (1) & $2.47(0.74)$ & $2.57(1.05)$ & $3.19(0.85)$ \\
\hline FEV $_{1}$ /FVC (\%) & $44.5(12 \cdot 9)$ & $47 \cdot 7(13 \cdot 5)$ & $59.9(9.6)^{\star}$ \\
\hline TLC (1) & $6.66(1.85)$ & $6.99(2 \cdot 17)$ & $6 \cdot 14(1 \cdot 37)$ \\
\hline FRC (1) & $4 \cdot 73(1 \cdot 65)$ & $4.89(1.65)$ & $3.75(1.06)^{\star}$ \\
\hline TLCo $(\mathrm{mmol} / \mathrm{kPa} / \mathrm{s})$ & $5.94(1.51)$ & $7 \cdot 05(2 \cdot 03)$ & $8 \cdot 40(2 \cdot 80)$ \\
\hline $\mathrm{Kco}(\mathrm{mmol} / \mathrm{kPa} / \mathrm{s} / \mathrm{l})$ & $1 \cdot 32(0 \cdot 42)$ & $1.68(0.53)$ & $1.72(0.52)$ \\
\hline
\end{tabular}

${ }^{\star} \mathrm{p}<0.05$ between corticosteroid groups.

$\mathrm{M} / \mathrm{F}$-male/female; N/A - not applicable; $\mathrm{FEV}_{1}$ - forced expiratory volume in one second; FVC-forced vital capacity; TLC-total lung capacity; FRC-functional residual capacity; TLCO-carbon monoxide transfer factor; $\mathrm{KCO}-$ transfer factor per unit lung volume. and values below $60 \%$ of these values were taken as abnormal (D A Jones, personal communication).

\section{STATISTICS}

Standard statistical methods to calculate the mean, standard deviation, standard error of the mean, and Pearson's correlation were used. An unpaired $t$ test was used to analyse the differences between the control group and matched patients on oral corticosteroids after ensuring that the two groups had equal variances by means of the $F$ test. A p value of less than 0.05 was taken as significant.

\section{Results}

Table 1 gives details of the mean age, steroid dose, duration of treatment, and lung function of the matched corticosteroid group and control group. The two groups were closely matched in terms of age, height, weight and all indices of lung function. Although the control group had lower indices of gas transfer (as would be expected from a group of patients with mostly chronic airflow limitation induced by smoking rather than asthma), the differences between the two groups did not reach statistical significance. Also shown in table 1 are the results from the additional 18 patients taking corticosteroids who, as a group, had significantly less severe airflow limitation than the group of 12 corticosteroid dependent patients. Table 2 summarises the respiratory and quadriceps strength for the three groups. Only one patient in the smaller corticosteroid group had evidence of quadriceps weakness. This patient had previously reported muscle weakness, but did not have abnormal respiratory pressures or weak sternomastoid muscles. Four patients in the control group had evidence of quadriceps muscle weakness.

The mean maximal mouth pressures for both the matched corticosteroid group and the control group were similar and within the normal range for adults as established previously in our laboratory (table 2). ${ }^{15}$ In the matched corticosteroid group, however, two patients had a Pimax or PEmax below the normal range for their sex as did five patients in the control group. Based on Fisher's exact test, there was no significant difference in the prevalence of patients with respiratory pressures below the normal range between the two groups. Of the five patients who had abnormal respiratory pressures in the control group, three had also had quadriceps weakness. In the 18 additional patients on corticosteroids, three were below the normal range for either PImax or PEmax.

The mean sternomastoid muscle TMRRs in the matched corticosteroid and control groups were similar (table 2) and were within the normal range established in this laboratory from 32 normal subjects (mean (SD) $9.62(1.91)$, range $5 \cdot 8-13 \cdot 44 \%$ force loss $/ 10 \mathrm{~ms})$.

The mean (SD) endurance time of headlift exercise was significantly longer in the control 
Table 2 Mean (SD) values of respiratory and peripheral muscle strength, endurance time, and fresh state TMRR

\begin{tabular}{|c|c|c|c|}
\hline & $\begin{array}{l}\text { Control group } \\
(n=12)\end{array}$ & $\begin{array}{l}\text { Corticosteroid group } \\
(n=12)\end{array}$ & $\begin{array}{l}\text { Additional corticosteroid } \\
\text { patients }(n=18)\end{array}$ \\
\hline PImax $\left(\mathrm{cm} \mathrm{H} \mathrm{H}_{2} \mathrm{O}\right)$ & $52 \cdot 1(22 \cdot 4)$ & $66 \cdot 1(24 \cdot 0)$ & $67 \cdot 4(26 \cdot 2)$ \\
\hline PEmax $\left(\mathrm{cm} \mathrm{H}_{2} \mathrm{O}\right)$ & $95 \cdot 7(49 \cdot 3)$ & $119 \cdot 3(52 \cdot 1)$ & $96 \cdot 1(32 \cdot 3)$ \\
\hline Quadriceps MVC (N) & $226(90)$ & $266(103)$ & $276(106)$ \\
\hline Sternomastoid MVC (N) & $80.9(22.5)$ & $82.3(28 \cdot 8)$ & $81 \cdot 1(24 \cdot 3)$ \\
\hline Endurance time (s) & $121(47)$ & $86(24)^{\star}$ & $102(36)$ \\
\hline $\begin{array}{l}\text { Fresh state TMRR } \\
\text { (\% force loss } 10 \mathrm{~ms})\end{array}$ & $10 \cdot 10(1 \cdot 95)$ & $10 \cdot 36(2 \cdot 02)$ & $10.94(2 \cdot 35)$ \\
\hline
\end{tabular}

${ }^{\star} \mathrm{p}<0.05 v$ control group.

PImax-maximum inspiratory mouth pressure; PEmax-maximum expiratory mouth pressure; MVC - maximal voluntary contraction; TMRR - twitch maximum relaxation rate.

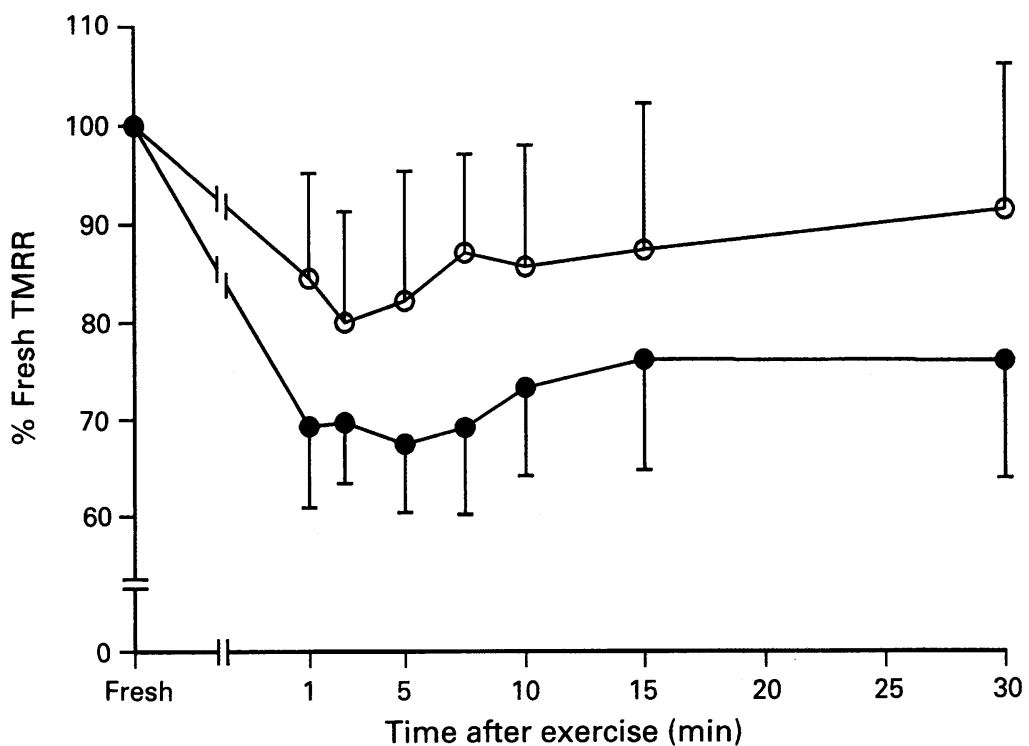

Figure 1 Mean percentage slowing and recovery of fresh state $T M R R$ after exercise in the corticosteroid group (O, $n=12)$ and the control group $(O, n=12)$. These are significantly different from each other at all times when measured up to 30 minutes.

group compared with the matched corticosteroid group (121(47)s $v 86(24) \mathrm{s}, \mathrm{p}<0.05)$. Despite less exercise, however, the mean percentage slowing from fresh state TMRR was significantly greater in the matched corti-

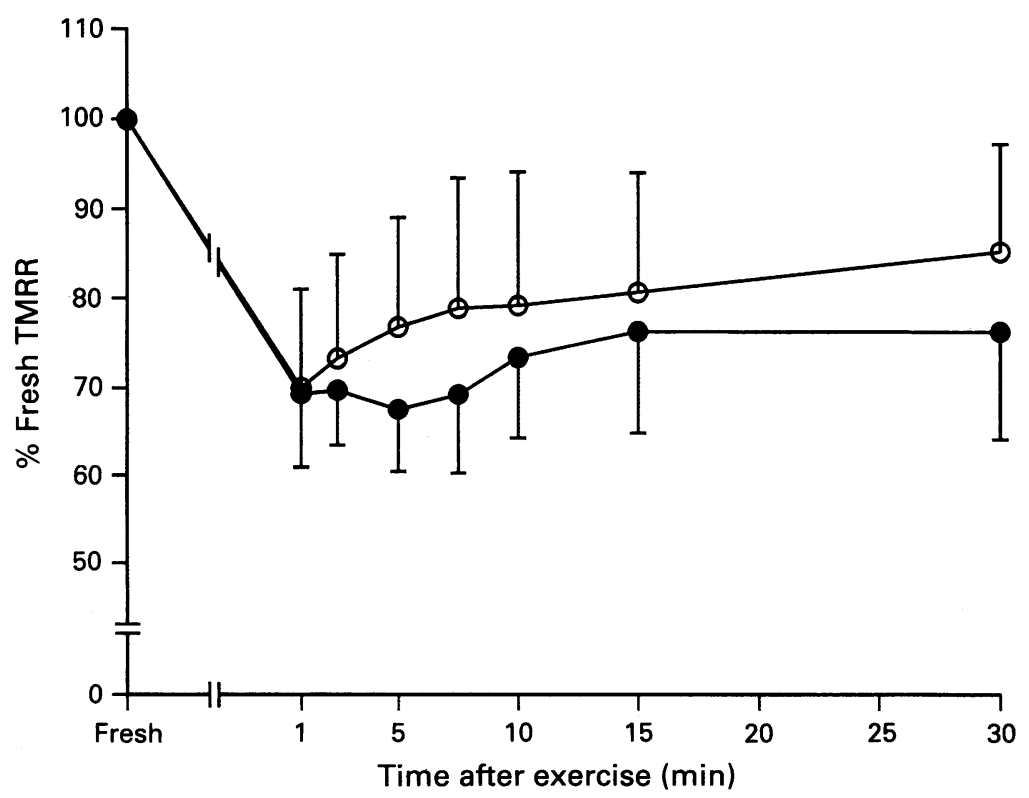

Figure 2 Mean percentage slowing and recovery of fresh state TMRR after exercise in the matched corticosteroid group $(\mathrm{O}, n=12)$ and the additional 18 patients taking corticosteroids (O). costeroid group and this recovered more slowly after exercise (fig 1). In the control group, two subjects showed little change or acceleration of the TMRR after exercise. These two subjects could have accounted for the significant differences between the two groups. If these two controls, together with the two corticosteroid patients with whom they were matched, were excluded from the $\overrightarrow{\vec{F}}$ analysis, however, the mean percentage slowing and rate of recovery of the TMRR between the two groups still remained significantly different.

The fall and recovery of the TMRR was similar between the smaller group of patients taking corticosteroids and the additional $18 \vec{\circ}$ patients taking corticosteroids (fig 2).

There was no correlation between any of the indices of muscle function with the dose $\overrightarrow{\overrightarrow{2}}$ of steroids, or with the duration of use of steroids, or with the product of these two variables.

\section{Discussion}

We have shown that there is little evidence of respiratory muscle weakness, as assessed by maximal mouth pressures, in asthmatic patients taking long term oral corticosteroid treatment compared with a control group of $छ$ patients with chronic airflow limitation. Patients taking corticosteroids had fresh state sternomastoid TMRRs well within the normal range and similar to the control group. Asthmatic patients taking corticosteroids, however, had significantly shorter sternomastoid exercise endurance time with signifi- $\overrightarrow{\overrightarrow{0}}$ cantly more slowing of the TMRR and slower 3 rate of recovery than controls. This suggests that the sternomastoid muscle in corticosteroid dependent asthmatic patients fatigues more easily and takes longer to recover from fatigue than in patients with equivalent severity of airflow obstruction but not taking oral corticosteroids.

The prolonged slowing of the TMRR in the asthmatic group shows a major advantage 0 of the TMRR over the more commonly used indicator of the fatiguing process, the maximum relaxation rate (MRR; measured after tetanic stimulation or maximum voluntary $\%$ contractions).1617 After fatiguing exercise, $N$ slowing of the sternomastoid TMRR lasts for $\mathrm{\omega}^{N}$ longer than the MRR, and seems to follow the time course of low frequency fatigue. ${ }^{9} \mathrm{O}$ Also, the sternomastoid muscle TMRR slows $\mathbb{\Phi}$ before the loss of force generating capacity, and the degree of slowing and rate of recovery of the TMRR is related to the preceding load. ${ }^{18}$ Therefore, slowing of the TMRR can indicate if the muscle is undergoing a poten- $\triangle$ tially fatiguing load. Comparison of the corticosteroid group with our previously published 8 results for 10 normal subjects without respi-은 ratory disease and exercised to the same degree of fatigue ${ }^{9}$ showed that the slowing? and recovery of the sternomastoid TMRR are similar (fig 3). Although these two groups are not directly comparable (the normal subjects were younger and had a different sex distribu- 


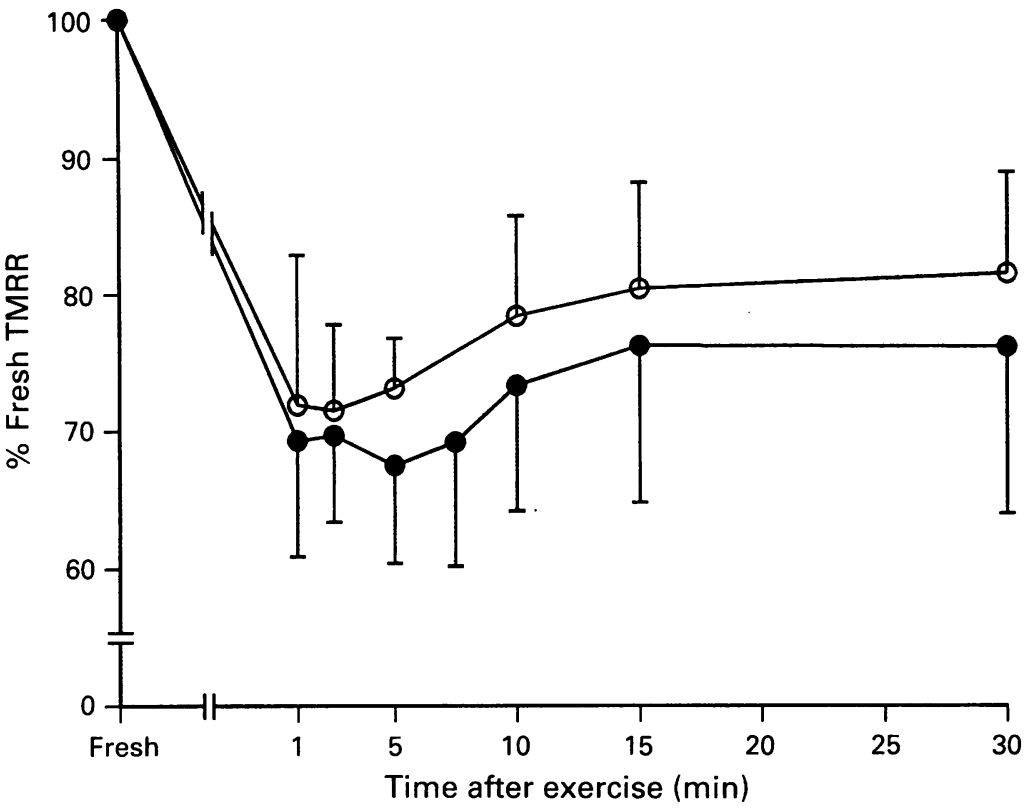

Figure 3 Mean percentage slowing and recovery of fresh state TMRR after exercise in the matched corticosteroid group $(\mathrm{O}, n=12)$ and previously studied normal subjects $(\bigcirc, n=10)$. mild to moderate airflow obstruction but were not taking long term oral corticosteroids. Their findings showed enhanced endurance of both inspiratory and expiratory muscles but not limb muscles in both asthmatic patients, and patients with chronic airflow limitation. They also suggested that this was due to a training effect that chronic or intermittent episodes of airflow obstruction had on the respiratory muscles. Our asthmatic patients, however, showed reduced endurance of the sternomastoid muscle compared with patients with chronic airflow limitation. This suggests that there is a difference between the sternomastoid and other muscles of respiration, or that there is a myopathic effect from the oral corticosteroids, or that steroids attenuated the training effects of a chronic respiratory load.

Another possible explanation for our findings could relate to differences in the two diseases we have studied. The load on the respiratory muscles in chronic airflow limitation is fairly constant, whereas it may be intermittent in asthma. All our asthmatic subjects, however, were studied in a stable condition and had severe airflow limitation in the stable state. Therefore, they would have a similar chronic load to that of the patients with chronic airflow limitation together with intermittent exacerbations, so should have exhibited a similar training effect. Also, our asthmatic patients could have performed less well because of bronchospasm induced by exercise. Although we did not measure lung function after exercise, no patients complained of worsening of asthma after the exercises, or required bronchodilators.

Few studies have examined the effect of long term oral corticosteroid treatment on the respiratory muscles of humans. One study has examined the effect of a short course of prednisolone (20 mg/day for 14 days) on normal subjects and found no change in respiratory pressures or endurance. ${ }^{7}$ Picardo et al ${ }^{8}$ examined a group of 34 patients with chronic severe asthma who had been taking an average dose of $11.9 \mathrm{mg}$ of prednisolone for a mean of 7.9 years (a higher mean dose but a shorter duration of treatment than in our group) and found no difference in respiratory or peripheral muscle strength when compared with a group of age, sex, height, and weight matched asthmatic patients. The control group was not well matched in terms of respiratory impairment, however, with the steroid group having a forced expiratory volume in one second $\left(\mathrm{FEV}_{1}\right)$ of $54 \cdot 1 \%$ of predicted compared with the control group with an $\mathrm{FEV}_{1}$ of $73 \%$ ( $\left.\mathrm{p}<0.001\right)$.

The clinical effect of therapeutic doses of corticosteroids on peripheral skeletal muscle is well known, ${ }^{12}$ but animal models of corticosteroid myopathy have produced conflicting results. Corticosteroids produce selective atrophy of fast twitch type II fibres in skeletal muscles ${ }^{1027}$ and in the diaphragms of various animals, ${ }^{1129-31}$ without change in the proportion of type I to type II fibres within the muscle. Although these studies show changes
Gandevia and colleagues have also found increased endurance in the respiratory muscles of patients with chronic airflow limitation and asthma. ${ }^{25} 26$ Their asthmatic patients had 
occurring within the muscle, the manifestation of the myopathy was variable. These inconsistent results may be due to the different animals used, different corticosteroids, and widely differing dose regimens.

Studies that have examined the endurance of corticosteroid treated diaphragms have also generated conflicting results; some reporting increased or unchanged endurance, ${ }^{1129}$ and others reduced endurance. ${ }^{3132}$ Picardo et al ${ }^{8}$ found that respiratory muscle endurance, as tested by breathing against an inspiratory resistance, was similar in a group of 10 patients treated with steroids and an anthropometrically matched control group. In our study, with patients more closely matched, the group treated with steroids had a significantly shorter endurance time when the sternomastoid muscle was tested by maximal headlift exercise. If atrophy occurs mainly in fast fatigue type II fibres, leaving behind a population of fatigue resistant type I fibres then, theoretically, the muscle should become less prone to fatigue. This does not, however, take into account the reduction in mass seen in corticosteroid treated muscles. ${ }^{1129} 30$

Finally, with regard to the effects of corticosteroids on the twitch contractile properties of muscle, some studies have reported no change in relaxation rate, ${ }^{29}{ }^{31}$ whereas others have reported a slowing of relaxation..$^{1130}$ Again, if corticosteroids produce atrophy of mainly fast twitch type II fibres, the contribution of slow twitch type I fibres should become more prominent and the relaxation rate of the muscle should become slower. A slow resting TMRR may therefore be an indication of loss of type II fibres. The mean TMRR of our steroid group was, however, similar to that of normal subjects and that of the control group.

In conclusion, although patients treated with corticosteroids show no significant reduction in muscle strength or respiratory pressures, there may be a reduced training effect on the respiratory muscles compared with patients with a similar respiratory impairment.

We are grateful to Dr GJ Gibson for his useful comments and criticisms, and Dr DA Jones for the predicted values for quadriceps strength in normal subjects. VHFM was funded by the Chest, Heart, and Stroke Association.

1 Khaleeli AA, Edwards RHT, Gohil K, McPhail G, Rennie MJ, Round J, et al. Corticosteroid myopathy: a clinical and pathological study. Clin Endocrinol 1983;18:155-66.

2 Perkoff GT, Silber R, Tyler FH, Cartwright GE, Wintrobe MM. Studies in disorders of muscle. XII. Myopathy due to the administration of therapeutic amounts of 17-hydroxycorticosteroids. Am F Med 1959, amounts

3 Afifi AK, Bergman RA, Harvey JC. Steroid myopathy. fohn Hopkins Med ₹ 1968;123:158-74.

4 Bowyer SL, LaMothe MP, Hollister JR. Steroid myopathy: incidence and detection in a population with asthma 7 Allergy Clin Immunol 1985; 76:234-42.

5 McFarlane EA, Rosenthal FD. Severe myopathy after status asthmaticus. Lancet 1977; ii:615.

6 Van Marle W, Woods KL. Acute hydrocortisone myopathy. $B M \mathcal{F}$ 1982;281:271-2.
7 Wang Y, Zintel T, Vasquez A, Gallagher CG. Corticosteroid therapy and respiratory muscle function in humans. Am Rev Respir Dis 1991;144:108-12.

8 Picado C, Fiz JA, Montserrat JM, Grau JM, FernandezSola J, Luengo MT, et al. Respiratory and skeletal muscle function in steroid-dependent bronchial asthma. $A m$ Rev Respir Dis 1990;141:14-20.

9 Mak VHF, Chapman F, James C, Spiro SG. Sternomastoid muscle twitch maximum relaxation rate: prolonged slowing with fatigue and post-tetanic acceleration. Clin Sci 1991;81:669-76.

10 Vignos PJ, Kirby AC, Marsalis PH. Contractile properties of rabbit fast and slow muscles in steroid myopathy. $\operatorname{Exp} \overline{\vec{A}}$ Neurol 1976;53:444-53.

11 Wilcox PG, Hards HM, Bockhold K, Bressler B, Pardy RL. Pathologic changes and contractile properties of the diaphragm in corticosteroid myopathy in hamsters: comparison to peripheral muscle. Am $\mathscr{f}$ Respir Cell Mol Biol 1989;1:191-9.

12 Cotes JE. Lung function. 4th edn. Oxford: Blackwells, 1979.

13 Black LF, Hyatt RE. Maximal respiratory pressures: nor- $\overrightarrow{0}$ mal values and relationship to age and sex. Am Rev mal values and relationship

14 Bugler JR, Mak VHF, Spiro SG. Measurement of respiratory pressures using a low cost disposable arterial pressure transducer [abstract]. Thorax 1991;46:291P.

15 Wilson SH, Cooke NT, Edwards RHT, Spiro SG. Predicted normal values for maximal respiratory pressures in caucasian adults and children. Thorax 1984;39: $\vec{\theta}$ 535-8.

16 Edwards RHT, Young A, Hosking GP, Jones DA. Human skeletal muscle function: description of tests and normal values. Clin Sci 1977;52:283-90.

17 Esau SA, Bellemare F, Grassino A, Permutt S, Roussos $\mathrm{C}$, Pardy RL. Changes in relaxation rate with diaphragmatic fatigue in humans. $f$ Appl Physiol 1983;54: 1353-60.

$18 \mathrm{Mak}$ VHF, Bugler JR, Spiro SG. Effect of increasing inspiratory work loads without task failure on the sternomastoid twitch MRR [abstract]. Am Rev Respir Dis 1991;143:A369.

19 Czerwinski SM, Kurowski TG, O’Neill TM, Hickson RC. Initiating regular exercise protects against muscle atrophy from glucocorticoids. If Appl Physiol 1987;63: 1504-10.

20 Falduto MT, Czerwinski SM, Hickson RC. Glucocorticoid-induced muscle atrophy prevention by exercise in fast-twitch fibers. $\mathcal{F}$ Appl Physiol 1990;69: 1058-62.

21 Seene T, Viru A. The catabolic effect of glucocorticoids in different types of skeletal muscle fibers and its dependence upon muscle activity and interaction with anabolic steroids. f Steroid Biochem 1982;16:349-52.

22 Gardiner PF, Hibl B, Simpson DR, Roy RR, Edgerton VR. Effects of a mild weight-lifting program on the progress of glucocorticoid-induced atrophy in rat hindlimb muscle. Pflugers Arch 1980;385:147-53.

23 Horber FF, Hoopeler H, Scheidegger JR, Grünig BE, Howald $\mathrm{H}$, Frey FJ. Impact of physical training on the $x$ ultrastructure of midthigh muscle in normal subjects $O$ and in patients treated with glucocorticoids. 7 Clin 3 Invest 1987;79:1 181-90.

24 Horber FF, Scheidegger JR, Grünig BE, Frey FJ. Oे Evidence that prednisone-induced myopathy is reversed by physical training. F Clin Endocrinol Metab 1985;61: 윽 83-7.

25 McKenzie DK, Gandevia SC. Strength and endurance of $D$ inspiratory, expiratory and limb muscles in asthma. $\mathrm{Am}$ 을 Rev Respir Dis 1986;134:999-1004.

26 Newell SZ, McKenzie DK, Gandevia SC. Inspiratory and $\mathrm{N}$ skeletal muscle strength and endurance and diaphragmatic activation in patients with chronic airflow limitation. Thorax 1989;44:903-12.

27 Gardiner PF, Botterman B, Eldred E, Simpson DR, Edgerton VR. Metabolic and contractile changes in fast and slow muscle of cat after glucocorticoid-induced $c$ atrophy. Exp Neurol 1978;62:241-55.

28 Gardiner PF, Edgerton VR. Contractile responses of rat fast and slow muscles to glucocorticoid treatment. Muscle Nerve 1979;2:274-81.

29 Moore BJ, Miller MJ, Feldman HA, Reid MB Diaphragm atropy and weakness in cortisone-treated $\overrightarrow{\mathbb{D}}$ rats. $\mathcal{f}$ Appl Physiol 1989;67:2420-6.

30 Viires N, Pavlovic D, Pariente R, Aubier M. Effects of steroids on diaphragmatic function in rats. $A m$ Rev
Respir Dis 1990;142:34-8.

31 Lewis MI, Monn SA, Sieck GC. Effect of corticosteroids on diaphragm fatigue, SDH activity, and muscle fiber size. F Appl Physiol 1992;72:293-301.

32 Ferguson GT, Irvin CG, Cherniack RM. Effect of corticosteroids on diaphragm function and biochemistry in the rabbit. Am Rev Respir Dis 1990;141:156-63. 